Journal of Teacher Education for Sustainability, vol. 23, no. 1, pp. 115-131, 2021

\title{
The Professional Development of Academic Staff in Higher Education Institution
}

\author{
Duc Huu Pham \\ International University, Vietnam National University HCMC, \\ Ho Chi Minh City, Vietnam
}

\begin{abstract}
Higher education is given increasing recognition by national governments and international agencies throughout the world to become a crucial incentive for sustainable development goals. In the national development of intellectual force at present, the Vietnam policy of education and training, which is of great importance, is the decisive factor for the economic growth and social development as set out by the government. Therefore, the educational development is the responsibility of both the government and the society. It is now clear that the academic staff in higher education institutions is the core force, playing a decisive role in ensuring the quality of higher education as in the case of the International University - Vietnam National University Ho Chi Minh City. The paper investigated the research studies by the university academic staff through their annual publications and the number of lecturers with Doctoral degrees and professorship. The results showed their research studies contributed to the development of the institution in particular, and at the same time predicted how much the stakeholders benefited from this in general. This study may contribute to developing the quality of higher education institutions regarding the promotion of international publications by the higher education faculties.
\end{abstract}

Keywords: academic staff, development, faculty, higher education institutions, international publications, decisive factor

\section{Introduction}

Currently, the process of training, using and developing human resources in higher education, especially teachers, is very important, and becomes the decisive factor for the success of socio-economic reform in Vietnam. The academic staff account for $80 \%$ of public employees nationwide. To meet the increasing demand of higher education organizations for human resources, the government always pays attention to building and developing the academic staff in the direction of quality standardization, especially focusing on ethics, lifestyle, professional conscience, and pedagogical qualifications, to meet the increasing demands of the educational cause in the industrialization and modernization of the country. Therefore, education and training development is the top national 
policy and one of the important driving forces of industrialization and modernization to build up the contingents of qualified teachers to meet quality requirements as reasonable and effective investments in establishing educational and training institutions to reach international standards (as cited in Pham, 2012).

In education, each educational organization plays a very important role, greatly influencing education quality, so the management of teaching affects the quality of training. In this process, the role of the faculty determines the existence and the quality of education (as cited in Le, 2019). This study discusses the planning for the development of lecturers in higher education institutions, taking into consideration the development of the academic staff at the International University - Vietnam National University Ho Chi Minh City (IU - VNU HCMC) in terms of the demand for quantity, quality, structure and development. Its educational development of human resources, in parallel with the development of the knowledge economy, is represented through the announcement of lecturers' publications. This research aimed to find out whether IU-VNU HCMC research articles for international journals would be able to be published papers in the Web of Science (WoS) and Scopus in the context of international integration. This study was taken as a basis for promoting the development of the professionalism of academic staff in higher education institutions in Vietnam and proposing possible solutions to the betterment of the teaching quality and hopefully promoting the passion in international publications by the higher education faculties.

\section{Literature Review}

This study will go through the key issues that contribute to the development of lecturers in higher education institutions through the understanding of international trends and Vietnam's higher education development strategies and policies, the training quality management at the tertiary level, the activities of scientific research and technology transfer in the knowledge economy, the building of academic environment in higher education institutions and the cooperation with domestic and international education and scientific research.

\section{International Trends, Development Strategy and Policy of Higher Education}

Universities have played a new and important role in the goals of sustainable developments (McCowan, 2016). There have been many interested international agencies such as the United Nations Educational, Scientific and Cultural Organization (UNESCO), the UN, the United Nations Development Program (UNDP), and the World Bank (WB), which have issued many policies and programs that influence universities (Beynaghi et al., 2016; Boni \& Walker, 2016) (as cited in Murillo-Vargas, Gonzalez-Campo, \& Brath, 2020). Challenges that higher education systems have had to face so far are fundamental changes regarding international and national circumstances (Shattock, 2014).

In Phan's research (2020), there are currently about 50 countries implementing extensive reforms in the educational sector because knowledge economy and globalization are evolving so rapidly that current educational systems hardly keep pace with these drastic changes. Ferreira, Martinsone and Talić (2020) indicate that teachers' performance quality and evaluation are undergoing an intense scrutiny (European Commission, 
2015; OECD, 2013), with the intense development of successful programs in the past two decades in an effort to enhance the quality of teacher preparation and teacher professional development. Therefore, throughout Europe, new policies have been set up to work out professional standards, to improve teacher preparation and to meet the demand of certification requirements. There has been an increase of investments in the programs to provide mentoring to new teachers and to support teachers' professional development.

According to Dzelzkalejja and Kapenieks sen (2018), 100 best universities in the world have always taken into important consideration such criteria as academic prestige, scholarly excellence, and intellectual horsepower. This ensures sustainable higher education, in which all components and participants seek positive harmony, democracy and participation in creating learning communities and organizations where functional, critical, and creative competencies are valued. It is, thus, necessary for an educational institution to have a certain set of characteristics.

\section{Characteristics for Developing Higher Education Institutions for Sustainability in the World}

Some countries are mentioned as typical examples of higher education for the purpose of sustainability, including China, the United States and Great Britain. China is a country that has recorded impressive achievements in higher education investment because the quality of education will ensure the maintenance of a competitive strength in the coming years (Le \& Truong, 2014). The Chinese government realized the importance of training and effective use of high-quality teachers and passed the Teacher Law, 1993 and the Education Law, 1995. These are the first laws to be passed that directly prepare teachers into the national legal system. They set the recruitment standards and qualifications that teachers must have before taking their positions at any school; specifically, the current teacher needs at least a Master's degree. Therefore, measures are taken to improve the quality as well as the effective use of the faculty in higher education institutions, including the increase of investments in improving the qualifications of teachers, improving ways to treat teachers, bettering teachers' lives and the working conditions of educational institutions. A comprehensive national policy is carried out to enhance teachers' qualifications, strengthening all educational reforms to meet the social demands in terms of quality and quantity. Attention is also paid to the ideology of lifelong learning, and to the gradual modernization in teacher training under the leadership of the state department of education.

The United States is also another example illustrating the effective development of a contingent of faculty in higher education institutions. The United States has concentrated resources to conduct talent training in some key fields at research universities. Therefore, in 2001, the United States applied a talent training program in science and technology, called "BEST" (i.e., Building Engineering and Science Talent) program, at many prestigious universities. The national research background has had a positive impact on research activities at universities, especially, on the quality of young talent training. As a result, about 3,000 patents are granted each year at universities in the United States. Training talents is mainly done on the basis of combining efficiency with research activities. Among 127 research universities in the United States in 2000, up to 
$78 \%$ of the total number of Bachelor's degrees, and $87 \%$ of the total number of Master's degrees in science and technology were awarded. According to BEST plan, major universities must assume the main responsibility in training young talented human resources. The method of training the talented human resources at US universities is always innovative, with the required application of modern technology in teaching and research, which is mandatory for professors at universities. The training method for talents has an emphasis on access to math tools and research (as cited in Trinh, 2017).

The building of academic staff quality at higher education institutions can be conceived at the secondary level, which can help promote high quality teaching at the tertiary level. The assessment of students' qualification at the secondary level may pave the way to facilitate academic staff in passing knowledge to university students. As the reality has proven, students' good achievements at secondary school have eased university professors' teaching methodology. The typical example is that the effective deployment of the preparation for higher education in the United Kingdom can be seen through the reforms of assessment of secondary education. According to Rogers and Spours (2020), the assessment of the reforms to all qualifications - GCSEs, A Levels, vocational qualifications and apprenticeships - has acclaimed a move towards final examinations, leading to the change in the grading of GCCEs; specifically, the use of the performance tables for 2017 and 2018 is based on a mixed economy of grades. The reforms are to refocus attention on the academic curriculum, to create more rigorous and in-depth learning, and to strengthen the technical education tradition. Consequently, the New Labor emphasis is given to a more diverse general education route and applied education.

Apart from the evaluation of students' qualification and the assessment of the reforms to all qualifications, the assessment of teachers is also crucial as this is part of their performance evaluation (OECD, 2009) since the competency-based training helps promote teachers' competency assessment (Roelofs \& Sanders, 2007, p. 124), which facilitates decision-making in teacher coaching. Moreover, accountability in the teaching profession can be acquired through the assessment of teachers' competence (as cited in Sumaryanta et al., 2018, p. 118).

\section{Trends, Development Strategy and Policy of Higher Education in Vietnam}

According to Lam (2019), since the 1990s, Vietnam's education and training development policy has been continuously improved through the Education Law (1991), the Education Law (1998), the revised Education Law (2005) on the basis of inheriting and developing the cultural values of the nation and absorbing the quintessence of world education philosophy such as humanistic education (including respect for people, and education for human sustainable development), lifelong learning, and building a learning society. Education and training must be considered the top national policy in Vietnam, with the mission of improving people's knowledge, training human resources, fostering talents because the humanities are the goal and driving force of socio-economic development. Therefore, an investment in education is an investment in development of a positive influence to properly apply the law of value, the law of interests, the law of competition, the training associated with the use of the labor market, and to limit the negative effects towards commercialization for education and training to promote lifelong learning and educational equity towards sustainability. 


\section{Training Quality Management at Vietnamese Universities}

The contribution of higher education is to provide millions of human resources with college and university qualifications. According to Nguyen (2012), this is a key force, the core of the process of industrialization and modernization of the country, and of national development in the period of renovation and international integration. The system of higher education institutions has covered the whole country (62 out of 63 provinces and cities having universities or colleges). The state investment in higher education increased rapidly, and the financial mechanism for higher education began to be reformed. The educational quality monitoring mechanism is implemented. Moreover, international relations are developing relatively rapidly at both the national and the local level.

The faculty members in universities are increasing in both quantity and professional quality. Knowledge, professional qualifications, and empirical experiences have been gradually improved in all aspects, positively contributing to the success of the national renovation. The ethical qualities of the teachers are increasingly stable. Foreign language performance and information technology skills are constantly being fostered and improved. From the policy perspectives, it can be seen that the building of a contingent of teachers in 20 years of innovation has made important changes in educational awareness and views that can be reflected in mechanisms, policies of training and management that have gradually met the country's requirements of socio-economic and sustainable development. Though the quality of the contingent of teachers in Vietnam universities is not currently fairly high, it can keep up with the development requirements of the country, society and integration trend. The quantity and quality of teachers at a university is the structure of its faculty, namely the number of lecturers holding Doctoral degrees, or the ratio of these lecturers and other teachers. This rate in Vietnam only reached $12.43 \%$, while the average at the Western universities is about $70 \%$. Taking into account the aforementioned considerations, the quality of Vietnamese university teachers is still very low. On the other hand, teachers' achievements in scientific research are still few. The number of articles published in prestigious international journals is limited (Dang \& Do, 2017).

\section{Cooperation and Association in Domestic and International Training and Scientific Research}

According to Phan (2019), in the current tendency of global integration, building Vietnamese universities according to international standards to create high quality human resources has become a major policy of the government, in which it is necessary to affirm an indispensable role in international co-operation. However, the management model and the training program adopted in foreign countries should be the sources for reference. The internal capacity should be built up to have a suitable direction for the domestic higher education institutions. University administrators and domestic scholars should be allowed to work independently in a reasonable and fair way, including the autonomous solutions to the issue of financial resources, the reform of mechanisms and policies, and especially the role of teachers.

As an increasing number of higher education institutions in the world require their academic staff to conduct scientific work for the practical application to get an economic 
profit (Reznik \& Vdovina, 2018), there has been a recent review of accreditation of higher education for 40 universities in Vietnam, which shows weakness in scientific research according to the set of standards for the quality accreditation of higher education in Vietnam. It can be seen that Vietnamese universities focus more on training than on scientific research. Long-established research institutions also focus on small-scale and outdated research studies. Vietnamese universities need to aim at solving more realistic and larger-scale issues of culture and education at ministerial and state levels. The evaluation results also showed that because the capability of scientific research at universities is still weak, the number and quality of scientific articles, professional books and papers published on research results of universities are very limited. It is vital to pay due attention to the development of a strategic plan to carry out scientific research with the involvement of the enactment of regulations and positive measures to promote the application of scientific results. Therefore, there should be more co-operation with local enterprises, research institutes and domestic and foreign universities in scientific research (Nguyen, 2018).

Another issue that should be brought into notice is the internationalization of higher education, which can enable the varieties of research ability. From the perspective of the intercultural dimension of visiting scholar programs, according to Zheng, PirbhaiIllich, Martin, and Wu (2020), the findings from the analysis of documents, post-visit written reflections, interviews and research diaries are presented to identify discourses influencing these programs at a strategic level. Also, the direct intercultural experiences of visiting scholars identify the discourses evident in the data at an interpersonal level. Furthermore, the counter-narratives in the data show a shift in the programs from intercultural to inter-epistemological concerns. The study shows that internationalization, interculturality and criticality together have provided a more complex picture of the processes at work as universities internationalize through partnership activities in spite of the intersection between interculturalism and internationalization.

\section{The Development of Lecturers in Higher Education Institutions in Vietnam}

Universities, similar to other industries, have to confront fierce competition to be top universities to become competitive, and so the most effective way is to update their practices through the quality of research performance (Ponnuswamy \& Manohar, 2016). Moreover, as faculty at higher education institutions are scholars, they have the need to teach and research at the same time so as to publish and get promoted and tenured (Quimbo \& Sulabo, 2014). The knowledge provided at academic institutes by these scholars is useful to be applied in practice if knowledge management is maintained in higher education institutions (Dhamdhere, 2015).

As Biesta (2015) stated, schooling is understood as the fulfillment of three functions: 1) the contribution to the development of each student as an individual, by recognizing their unique characteristics and potentials, and by developing their ability to act autonomously and independently; 2) the socialization of students into ways of thinking and acting, vis-à-vis educational disciplines, that is, to help students think like a natural or social scientist so as to develop prosocial values, behaviors and attitudes regarding peers, adults and the world outside the school environment; 3 ) the teaching of subject-matter knowledge, skills and values to bring the high quality to the students in their future active roles in society. 
For vocational qualifications or well-qualified status to live in complex modern societies, Biesta (2015) views subjectification, socialization, qualification as functions of schooling, which, in practice, often contradict each other. Moreover, these functions are under continuous change because the nature of education is often open (in interaction with societal contexts and environments), semiotic and discursive (in involvement with interpretations and meaning-making), and recursive (in previous educational encounters that inform future encounters) (as cited in Cain, Brindley, Brown, Jones, \& Riga, 2019).

Therefore, the process of training, using and developing human resources in higher education, especially the faculty, is very important because this is the contingent of high-level multidisciplinary professional teachers, which is the decisive factor for the success of the socio-economic reform in Vietnam. Thus, the development of the academic staff, to which great attention should be paid by higher education institutions, is considered to be the main driving force to improve the quality of training, scientific research and technology transfer in the development trend of the economy (as cited in Nguyen, 2015).

Up to now, studies have dealt with problematic questions, indirectly associating them with teacher professional development. Therefore, typical research is needed to provide a conceptual framework for professional development processes of academic staff and for measuring the success, which can be reflected through the perspective of sustainable development. The field of changing higher education is now the mission, responsibility and role of universities that can be seen through the quantitative and qualitative analysis to better understand the correlation between university mission and performance. Accordingly, in this study, the views on the notions of the phenomena of sustainability, especially in terms of pedagogy and sustainable education in the higher education context, can be addressed as the goal and objectives of the study in the following part of the article.

\section{Methodology}

From what has been discussed above, the goal of this study was to find out how such an English-medium higher education institution as International University, Vietnam National University Ho Chi Minh City (IU-VNU HCMC) promoted its lecturers' professional development and whether the publications in the journals indexed in WoS and Scopus would affect their lecturers. More specifically, the objectives of this study address the following research questions.

\section{Research Questions}

1. How does IU-VNU HCMC lecturers' professional development help them in teaching their content subjects?

2. To what extent do the journal publications affect IU-VNU HCMC lecturers in teaching?

3. What are IU-VNU HCMC lecturers' beliefs to the rate of publications? 


\section{The Case of IU-VNU HCMC}

The research design of this study was to present the descriptive case study of the IU-VNU HCMC through data collection, measurement, and analysis regarding the professional development of academic staff at higher education institutions in Vietnam. The research used the quantitative approach with the collected data of the number of professors, associate professors, and Doctoral degree holders at IU-VNU HCMC, their average evaluation score and university's average score, and their publications from academic years 2016 to 2020. After the data were measured, there was a critical analysis to answer the research questions.

Ho Chi Minh City is a key economic region with advantages in size and quality of the most dynamically developing industries of the country in many socio-economic fields, especially the development of industrial focus. Therefore, the issue of building well-qualified academic staff at universities, especially at IU-VNU HCMC, where the author is working, is the decisive force that directly contributes to the training of highlevel multi-disciplinary human resources for the socio-economic fields of Ho Chi Minh City as well as the whole country. This is an urgent need and is a top priority in the present and future period.

IU-VNU HCMC has fully and relatively effectively implemented the content system for building and developing a contingent of well-qualified teachers from the time of planning, recruiting, using and evaluating to the time of training and retraining, planning and implementation of policies to build and develop the academic staff, especially towards the building of a contingent of teachers for public educational organizations. The work of building and developing teachers in IU-VNU HCMC is quite strong in many aspects regarding the organizational management in using and evaluating as well as in planning and implementing the policy regime for the faculty. This can be seen in the work of remuneration, encouragement, and creation of favorable conditions for facilities, working environment and income to enhance the life of the faculty of the University (www.https://hcmiu.edu.vn/en/introduction/).

With its strategic goal to become one of the leading research-oriented universities in Vietnam, IU-VNU HCMC is trying to become a training institution that receives reliable co-operation from reputable educational and scientific research partners in the world, from local and regional businesses. IU-VNU HCMC has implemented policies to encourage scientific research activities through well-paid salaries and a rewarding mechanism for each paper of WoS (or Scopus), international journal articles published in excess of requirements, and for rewarding teachers and outstanding academic units of the year.

IU-VNU HCMC promulgates and implements regulations on the registration and implementation of university-level research topics regarding periodicity, potentiality, market demand, focusing on ethics in scientific research, management of intellectual property, and management of scientific and technological activities. IU-VNU HCMC also develops policies to encourage students to do research with university scientists, to recognize and to reward students with good academic and research achievements. 


\section{Results}

The Number of Professors, Associate Professors, and Doctoral Degree Holders at IU-VNU HCMC

Since its establishment in 2003, IU-VNU HCMC has attracted high-quality human resources, including many leading experts with excellent research capacity and experience from famous universities in the world. Currently, there are 5 professors, 27 associate professors, and 88 Doctoral degree holders (Table 1), who are working as tenured lecturers. IU-VNU HCMC has strengthened its research capacity through the investment of laboratories from capital construction, tuition fees and other mobilization sources. The large-scale laboratories, which have been in effective operation, are algae technology laboratory, human and machine communication laboratory, laboratory of biomedical engineering, laboratory of ultra-high frequency microchip and application of embedded systems, laboratory reprogramming cell, laboratory strengthening capacity for in-depth research in biomedical engineering.

\section{Table 1}

The Number of Professors, Associate Professors and Doctoral Degree Holders at IU-VNU HCMC

\begin{tabular}{clccc}
\hline No. & \multicolumn{1}{c}{ Department/School } & Professors & $\begin{array}{c}\text { Associate } \\
\text { Professors }\end{array}$ & $\begin{array}{c}\text { Doctoral degree } \\
\text { holders }\end{array}$ \\
\hline 1 & Board of Rectors & 1 & 2 & 2 \\
2 & Biomedical Engineering & & 3 & 7 \\
3 & Biotechnology & 1 & 11 & 19 \\
4 & Business Administration & & 4 & 25 \\
5 & Civil Engineering & & 2 & 2 \\
6 & Information Technology & & 1 & 7 \\
7 & Electronics \& Telecommunications & & 1 & 9 \\
8 & English Linguistics & & 0 & 2 \\
9 & Industrial \& Systems Engineering & 3 & 2 & 7 \\
10 & Maths & & 1 & 2 \\
11 & Physics & & 2 & 2 \\
12 & Environmental Engineering & 5 & 27 & 88 \\
& Total & & & 4 \\
\hline
\end{tabular}

Source: Report from the Human Resources, IU-VNU HCMC.

\section{IU-VNU HCMC Lecturers’ Professional Development}

End-of-course student evaluations are frequently used to evaluate university faculty teaching. However, employing final student feedback has been found to be instrumental in informing faculty about instructional quality and improving student learning outcomes. This study examined and compared the results of the evaluation at the institutional level and the individual level in each department and each school of IU-VNU HCMC. The final test student feedback survey at departments and schools of IU-VNU HCMC, and of untenured and tenured lecturers was completed by 612 students over two years for 
courses taught at 10 departments and schools of IU-VNU HCMC. The survey used a 5 -point Likert scale ranging from "strongly disagree”, “disagree”, "neutral”, "agree”, to "strongly agree". The results indicated that the final test student feedback offered insights for IU-VNU HCMC faculty. In addition, when the faculty make instructional changes based on the data, students' responses improve since the fact that both lecturers and students possess the background knowledge of disciplinary areas can facilitate their learning. Based on the statistics of student feedback through the evaluation, the most important question of which this study focused on was: "Is the course helpful (including knowledge, skills and improvement of attitudes towards study and work, etc.)?. The results are provided in Table 2.

\section{Table 2}

Individual's Average Evaluation Score and University's Average Score, Academic Year 2019-2020

\begin{tabular}{clcc}
\hline No. & \multicolumn{1}{c}{ Department/School } & $\begin{array}{c}\text { Individual's average } \\
\text { evaluation score }\end{array}$ & $\begin{array}{c}\text { University's average } \\
\text { score }\end{array}$ \\
\hline 1 & Biomedical Engineering & 4.44 & 4.32 \\
2 & Biotechnology & 4.37 & 4.32 \\
3 & Business Administration & 4.28 & 4.32 \\
4 & Civil Engineering & 4.53 & 4.32 \\
5 & Computer Science \& Engineering & 4.24 & 4.32 \\
6 & Electronical Engineering & 4.28 & 4.32 \\
7 & English & 4.32 & 4.32 \\
8 & Industrial \& Systems Engineering & 4.32 & 4.32 \\
9 & Mathematics & 4.22 & 4.32 \\
10 & Physics & 4.39 & 4.32 \\
\hline
\end{tabular}

Source: Report from the Center for Quality Management, IU-VNU HCMC.

\section{Lecturers' Writing Papers for International and Domestic Journals}

Disseminating research and the knowledge base within a university is important for university management and policy development. Scientific writing in disciplines underpins research, the results of which are of much use if they are distributed for peer reference. Thus, the ability and the time allocation for IU-VNU HCMC lecturers to write are important in translating their knowledge into empirical research for findings. Many academics agree that writing for publication is one of the most difficult aspects of the process of research to improve lecturers' knowledge in teaching. All the data utilized in this study emanated from the IU Office of Research and Development as can be seen in Tables 3 and 4. 
Table 3

The Statistics of IU Lecturers' Publications from 2016 to 2020

\begin{tabular}{|c|c|c|c|c|c|}
\hline Type of publication & 2016 & 2017 & 2018 & 2019 & 2020 \\
\hline Papers in international journals & 132 & 131 & 125 & 48 & 37 \\
\hline Papers in international journals in WoS (+ Scopus) & 78 & 73 & 81 & 101 & 105 \\
\hline Papers in domestic journals & 79 & 60 & 48 & 82 & 43 \\
\hline Papers in international conference proceedings & 193 & 164 & 107 & 152 & 144 \\
\hline Papers in domestic conference proceedings & 32 & 14 & 15 & 12 & 5 \\
\hline $\begin{array}{l}\text { Other types of publications, editor for conference } \\
\text { proceedings, author of books, or chapter(s) of a } \\
\text { book, etc. }\end{array}$ & 17 & 9 & 9 & 19 & 12 \\
\hline Total (papers) & 453 & 378 & 304 & 414 & 345 \\
\hline
\end{tabular}

Source: Report from the Office of Research \& Development, IU-VNU HCMC.

A two-way group-independence chi-square test was performed to assess the distribution of the number of publications in the two groups of non-WoS (and nonScopus) and WoS (and Scopus) from 2016 to 2020 at IU-VNU HCMC. The corresponding contingence table is shown below.

Table 4

Chi-Square Test for Association regarding the Publications and the Year of Publications

\begin{tabular}{lcccccc}
\hline \multicolumn{1}{c}{ Publications } & 2016 & 2016 & 2018 & 2019 & 2020 & All \\
\hline Non-WoS \& Non- & 375 & 305 & 223 & 313 & 240 & 1456 \\
Scopus & 348.2 & 290.6 & 233.7 & 318.3 & 265.2 & \\
WoS \& Scopus & 78 & 73 & 81 & 101 & 105 & 438 \\
& 104.8 & 87.4 & 70.3 & 95.7 & 79.8 & \\
All & 453 & 378 & 304 & 414 & 345 & 1894 \\
\hline
\end{tabular}

Chi-Square Test

\begin{tabular}{lccc}
\hline & Chi-Square & DF & P-Value \\
\hline Pearson & 24.845 & 4 & 0.000 \\
Likelihood Ratio & 24.873 & 4 & 0.000 \\
\hline
\end{tabular}

The effect size of Cramer's V-square was 0.1145 , with a $95 \%$ CI [0, 0.0485]. The formal statistical results of the test were: Likelihood Ratio $=24.873, \mathrm{df}=4, \mathrm{P}<0.001$. Therefore, there is statistical difference in the distribution in the number of publications in the two groups of Non-WoS (\& non-Scopus) and WoS (\& Scopus) from 2016 to 2020 at IU-VNU HCMC.

The percentage of publications per lecturer holding a Doctoral degree shows the ability and time allocation of IU lectures in writing papers for international journals and writing WoS (and Scopus) papers in the context of international integration through the consideration of lecturers' beliefs to the rate of publications as can be seen in Table 5 . 


\section{Table 5}

Average Percentage of Publications per Lecturer Holding a Doctoral Degree

\begin{tabular}{lccccc}
\hline & 2016 & 2017 & 2018 & 2019 & 2020 \\
\hline $\begin{array}{l}\text { Average percentage of publication per lecturer } \\
\text { holding a Doctoral degree }\end{array}$ & 1.4 & 1.4 & 1.2 & 2.6 & 2.1 \\
$\begin{array}{l}\text { Average percentage of WoS (and Scopus) publica- } \\
\text { tions per lecturer holding a Doctoral degree }\end{array}$ & 0.8 & 0.8 & 0.8 & 0.8 & 0.9 \\
\hline
\end{tabular}

Source: Report from the Office of Research \& Development, IU-VNU HCMC.

\section{Discussion}

\section{Lecturers’ Professional Development in Teaching Content Subjects}

For the first research question: "How does IU-VNU HCMC lecturers' development help them in teaching their content subjects?", the survey data from the evaluation showed (Table 2) that the scores to evaluate lecturers ranged from 4.22 to 4.44 (with the highest being 5.0) at the individual level and maintained 4.32 at the institutional level. This assessment is quite important since it reflects whether the lecturers have applied suitable teaching methods to make their teaching effective to the students. Now when the demand for twenty-first century competencies for all students allows for the establishment of the currently implemented projects in most education systems (UNESCO, 2017a), many educational systems have concentrated more on competenceoriented curricula and student assessment (Kohl \& Hopkins, 2020). The assessment also indicates the teacher identity. University lecturers would like to affirm themselves under the university and peer pressure. This involves the identification of the teaching profession and the contextually constructed perceptions of what kind of teacher one wants to be (Beauchamp \& Thomas, 2009). With regard to the university context, the peer pressure also comes from peer review of teaching, which includes the evaluation through observations and discussions. However, only a few approaches have been assessed in order to determine the strengths and weaknesses of peer review of teaching (Biasutti, Baz, \& Alshawa, 2016). Therefore, research efforts have been exerted to explore the interplay between different forms of power, practices of policy and teacher identity (as cited in Gu \& Lai, 2019).

\section{The Effect of International Publications on Lecturers in Teaching at IU-VNU HCMC}

For the second question: "To what extent do the journal publications affect the lecturers in teaching at IU-VNU HCMC?”, the use of a two-way group-independence chi-square test for the data in Tables 3 and 4 brought about the effect size (Cramer's V-square: 0.1145), (95 \% CI: 0, 0.0485) and the formal statistical results (Likelihood Ratio $=24.873, \mathrm{df}=4, \mathrm{P}<0.001)$. It is clear that there is statistical significance in the distribution in the number of publications in the two groups of Non-WoS (\& non-Scopus) and WoS (\& Scopus) papers from 2016 to 2020 at IU-VNU HCMC. The null hypothesis is rejected. It is likely that the group of non-WoS ( $\&$ non-Scopus) papers will be able to keep the pace with the group of WoS (\& Scopus) papers. IU-HCMC, like other domestic 
or foreign universities, is responsible for the care of its staff and of the research participants that it recruits. As Murillo-Vargas, Gonzalez-Campo, and Brath (2020) found out, since the focus of Scopus is on sustainability and the environment and the focus of WoS is on the role of education in sustainability, this will help promote the professional development that targets the sustainable development goals in universities.

\section{Lecturers' Beliefs to the Rate of Publications}

For the third question: "What are the lecturers' beliefs to the rate of publications?", the data from Table 5 showed the average percentage of publications per lecturer holding a Doctoral degree out of the whole number of IU-VNU HCMC lecturers $(\mathrm{N}=120$, which consists of 5 professors, 27 associate professors, and 88 Doctoral degree holders), and the average percentage of WoS (or Scopus) publications per lecturer holding a Doctoral degree. Their beliefs were consolidated with the positive results presented in Table 5, where the average percentage of publications per IU-VNU HCMC lecturer ranged from 1.4, 1.4, 1.2, 2.6 to 2.1 for years 2016, 2017, 2018, 2019 to 2020, respectively; and the average percentage of WoS (or Scopus) publications per IU-VNU HCMC lecturer ranged from $0.8,0.8,0.8,0.8$ to 0.9 for years $2016,2017,2018,2019$ to 2020 , respectively. There has been an increasing pressure on individuals to publish their works from IU-VNU HCMC perspective as a research-oriented university. At IUVNU HCMC, research papers published in international journals (in WoS or Scopus) are important to illustrate the nature of research studies being undertaken and the development of a particular field or area of expertise. This usually brings prestige to the university.

Publications are also of great importance to individuals for career advancement. In order to write papers, both the knowledge of lecturers' subjects and the ability of using English to write are required, thus consolidating the application of their disciplines. Moreover, for the lecturers' writing efficiency, IU-VNU HCMC has established a writing center modelled after those in the foreign universities (where students and lecturers receive help if they need to have their papers revised before submitting them to journals for publication). The writing center ensures the revision of research papers (lectures' articles and students' graduation theses at undergraduate and graduate levels) regarding research format and language use. The main function of the writing center is to support IU students and lecturers who want to make improvements in their academic English writing.

The results obtained from the qualitative and quantitative analysis in the study predict that the sustainability of higher education in Vietnam will be ensured if similar domestic higher education organizations have the same orientation towards the enhancement of academic human resources.

\section{Implications and Recommendations}

It is also necessary to look back at the research study of building teaching force at IU-VNU HCMC in the past years (2016-2020): the focus on planning, management; the selection of lecturers, senior lecturers to gradually build up teaching force; the focus on the use and evaluation of teachers; regularly performing the training and retraining 
of teachers associated with scientific research; organization and implementation of policies and conditions to support teachers. Specifically, four groups of solutions are proposed to contribute to improving the work of building teachers: 1) Working out the planning for recruiting teachers; 2) Planning to build a contingent of well-qualified teachers; 3) Encouraging teacher competency; fostering each group of teachers at the university; 4) Renewing forms of fostering, creating conditions for the organization of fostering pedagogical competencies, training management, and scientific research.

For these solutions to go into effect, first of all, more autonomy should be given to higher education institutions. Second, it is recommended that there should be clear definitions for the preferential policies such as salary, career preference allowances and seniority allowances for teachers. This policy could attract excellent graduates, domestic and foreign scientists to be tenured lecturers, to improve their qualifications to work for higher education institutions. Third, there must be research to adjust circulars on the guidelines for revenue and expenditure in scientific research projects.

Furthermore, it is necessary to plan the scale of university training development in order to focus development resources of each member university in the Vietnam National University Ho Chi Minh City, and to avoid wasting the state budget and societal contributions in university training. It is necessary to have policies to encourage facilities and finance to support teachers to improve the quality of training and fostering, effectively developing and using the faculty of teachers, increasing their guaranteed income and motivation for their workplace.

It is also necessary to continue to strengthen and improve the quality of recruitment planning, use, evaluation, training and retraining, and implement the policy of building and developing staff, especially remuneration, encouragement, and facilitation in terms of facilities, working environment and income, to improve the life of teachers. It is important to evaluate and build a contingent of teachers on the basis of the effectiveness and quality of the university training and researching, and to gradually implement the solutions that this research study has proposed.

To enhance the effectiveness and quality of the university education and training and researching in the current context of international as well as domestic higher education, especially in the Covid-19 pandemic, the emphasis should be placed on the online education since in the organization of distance learning process, and students must rely on themselves in the majority of study courses (Vasilevska, Rivza, Alekneviciene, \& Parlińska, 2017). In this case, the teacher can develop the role of directing and the student can develop the role of acting.

As for the four groups of solutions mentioned above, the study indicates that the model for the professional development of academic staff at higher education institutions in Vietnam towards sustainability can be successfully employed through the combination of cultural and economic advantages inherently conferred in different countries, in spite of different ideologies. Concerning the development of higher education towards sustainability or quality of higher education, Vietnam is now following the elective examples of Western countries, and of the Eastern European countries and of countries that share similar settings with Vietnam, especially in the current context of international integration when there is an increasing number of international students coming to Vietnam to study and conduct research. 


\section{Conclusion}

The well-qualified faculty is the decisive factor in the training process. If an educational institution has a strong team of teachers in terms of quantity and quality, with good expertise, good ethical qualities, and the passion for the career, it will be the driving force to directly improve the teaching and learning quality. University education is a high-level training activity that has made many positive contributions to the assertion of the position of IU-VNU HCMC, used in this study as a typical example to illustrate the professional development of academic staff at higher education institutions as the IU-VNU HCMC has hands-on experience drawn from performing this strategic mission. With a vision for the coming years, the IU-VNU HCMC will surely have a strong and sustainable development, providing the training of highly qualified human resources to meet the requirements of the country's renovation, industrialization, and modernization in the context of current integration, affirming and maintaining the position of IU-VNU HCMC in the network of key educational institutions in South Vietnam. As Vietnam is implementing the cause of renewal, accelerating its industrialization and modernization for the goal of creating a rich population in a strong country with democracy, equality, civilization, and with a steadfast step toward a better society, it is recommended that further research should be on an active preparation to acquire strong intellectual resources and promote them effectively to successfully achieve the aforementioned goal.

\section{References}

Biasutti, M., Baz, T., \& Alshawa, H. (2016). Assessing the infusion of sustainability principles into University Curricula. Journal of Teacher Education for Sustainability, 18(2), 21-40. https://doi.org/10.1515/jtes-2016-0012

Cain, T., Brindley, S., Brown, C., Jones, G., \& Riga, F. (2019). Bounded decisionmaking, teachers' reflection and organisational learning: How research can inform teachers and teaching. British Educational Research Journal, 45(5), 1072-1087.

Dang, X. H., \& Do, T. T. Hang. (2017). Solutions to improve the capacity to adapt to change of education human management in education in the context of current education innovation in Vietnam. The Journal of Science - Vietnam National University, 32(3).

Dhamdhere, S. N. (2015). Importance of knowledge management in the higher educational institutes. Turkish Online Journal of Distance Education, 16(1), 162-183.

Dzelzkalēja, L., \& Kapenieks, J. Sen. (2018). Contradictions in higher education. Journal of Teacher Education for Sustainability, 20(1), 124-144. https://doi.org/10.2478/ jtes-2018-0008

Ferreira, M., Martinsone, B., \& Talić, S. (2020). Promoting sustainable social emotional learning at school through relationship-centered learning environment, teaching methods and formative assessment. Journal of Teacher Education for Sustainability, 22(1), 21-36. https://doi.org/10.2478/jtes-2020-0003

Gu, M. M., \& Lai, C. (2019). An ethical analysis of how ESL teachers construct their professional identities through the use of information technology in teaching. British Educational Research Journal, 45(5), 918-937.

Kohl, K., \& Hopkins, C. (2020). Learnings from the \#IndigenousESD Global Research: Twenty-first century competencies for all learners. Journal of Teacher Education for Sustainability, 22(2), 90-103. https://doi.org/10.2478/jtes-2020-0018 
Lam, N. T. (2019). Educational development policy of Japan and Vietnam (from the time of innovation). Proceedings of the International Scientific Seminar, 410-416.

Le, T. A., \& Truong, V. T. (2014). Experiences of several countries on building and developing intellectual teams. Journal of Science, University of Education, Ho Chi Minh City, 60.

McCowan, T. (2016). Universities and the post-2015 development agenda: An analytical framework. Higher Education, 72(4), 505-523.

Murillo-Vargas, G., Gonzalez-Campo, C., \& Brath, D. (2020). Mapping the integration of the Sustainable Development Goals in Universities: Is it a field of study?. Journal of Teacher Education for Sustainability, 22(2), 7-25. https://doi.org/10.2478/jtes2020-0013

Nguyen, D. D. (2015). Building teams of well-qualified teachers at Dong Nai University (Master' thesis, the University of Social Sciences and Humanities, VNU HCMC).

Nguyen, T. T. H. (2012). Building teams of college teachers - Reality and solutions. Journal of Science, 110-116.

Nguyen, T. T. T., \& Phuong, H. T. (2019). The policy on developing university teachers in Vietnam to meet the requirements for the innovation of undergraduate education. Journal of the Science and Education of the University of Haiphong: EducationSocio-Humanities, (37), 33.

Nguyen, V. H. (2018). The relationship between the university and the enterprise in the research, technology transfer and application of the Triple Helix model to promote this relationship in Vietnam. Hue University Journal of Science: Economics and Development, 127(5a), 119-131.

Pham, V. D. (2012). The role of human resources in the process of industrialization and modernization in Vietnam. Journal of Vietnam Social Sciences, (4), 13.

Phan, M. T. (2020). Developing a team of experts in the mission to develop the training of the university. Materials in refresher courses.

Phan, P. H. (2019). The role of international cooperation for high-quality human resource training Vietnamese universities-experience lessons. Journal of Science, Van Lang University, (13), 27.

Ponnuswamy, I., \& Manohar, H. L. (2016). Impact of learning organization culture on performance in higher education institutions. Studies in Higher Education, 41(1), 21-36.

Quimbo, M. A. T., \& Sulabo, E. C. (2014). Research productivity and its policy implications in higher education institutions. Studies in Higher Education, 39(10), 19551971.

Report from the Center for Quality Management, IU-VNU HCMC.

Report from the Department of Research and Development \& Science, IU-VNU HCMC.

Report from the Human Resources, IU-VNU HCMC.

Reznik, S. D., \& Vdovina, O. A. (2018). Regional university teacher: Evolution of teaching staff and priority activities. European Journal of Contemporary Education, 7(4), 790-803.

Rogers, L., \& Spours, K. (2020). The great stagnation of upper secondary education in England: A historical and system perspective. British Educational Research Journal.

Shattock, M. (Ed.). (2014). International trends in university governance: Autonomy, self-government and the distribution of authority. Routledge. 
Sumaryanta, Mardapi, D., Sugiman, \& Herawan, T. (2018). Assessing teacher competence and its follow-up to support professional development sustainability. Journal of Teacher Education for Sustainability, 20(1), 106-123. https://doi.org/ 10.24 78/jtes-2018-0007

Trinh, N. T. (2017). The development policy of the university education: The success in developed countries and the lessons for Vietnam. Journal of Educational Research, Vietnam National University, Hanoi, 33(1), 81-90.

Vasilevska, D., Rivza, B., Alekneviciene, V., \& Parlińska, A. (2017). Analysis of the demand for distance education at Eastern and Central European higher education institutions. Journal of Teacher Education for Sustainability, 19(1), 106-116. https://doi.org/10.1515/jtes-2017-0007

www.https://hcmiu.edu.vn/en/introduction/

Zheng, H., Pirbhailllich, F., Martin, F., \& Wu, L. (2020). Internationalisation of higher education: A critical analysis of the intercultural dimension of a visiting scholar programme. British Educational Research Journal.

Correspondence concerning this paper should be addressed to Duc Huu Pham, Associate Professor, Department of English, International University, Vietnam National University, Ho Chi Minh City, Vietnam. Email: phduc@hcmiu.edu.vn 